CP, 2013 , No3, pp. 51-63. ISSN 2014-6752. Girona (Catalunya). PARNAIBA, Cristiane dos Santos y GOBBI, Maria Cristina: MULHERES NA POLÍTICA E NA MÍDIA BRASILEIRA: BREVE HISTÓRICO E CENÁRIO ATUAL. Womens in politic and brazilian

Media: A brief history and actual stage.

Recibido: 05/12/2013 - Aceptado: 27/12/2013

\title{
MULHERES NA POLÍTICA E NA MÍDIA BRASILEIRA: BREVE HISTÓRICO E CENÁRIO ATUAL
}

\section{Women in politics and brazilian Media: A brief history and actual stage}

\author{
Autoras: PARNAIBA, Cristiane dos Santos; GOBBI, Maria Cristina \\ Mestranda - Universidade Estadual Paulista Júlio de Mesquita Filho - Brasil-cris_parnaiba@yahoo.com.br \\ Profesora Titular - Universidade Estadual Paulista Júlio de Mesquita Filho - Brasil-mcgobbi@terra.com.br
}

\section{Resumo}

O Brasil foi um dos quatro países da América Latina a eleger, neste século XXI, pela primeira vez uma mulher para o cargo de presidente. Mas será que o fato de se ter uma mulher no mais alto cargo da República reflete a realidade da participação política feminina brasileira? E como será a representação feminina na mídia do país? Para responder estas perguntas, este artigo faz uma revisão bibliográfica destes temas, mostrando que, apesar de termos uma mulher no mais alto posto da República, a participação política feminina e sua representação na mídia está aquém do desejado.

\section{Palavras-chave}

Brasil; Política; Mulher; Participação política feminina; América Latina.

\begin{abstract}
Brazil was one of the four countries of Latin America to be elected in this century, the first time a woman for president. But does the fact of having a woman in the highest office of the Republic reflects the reality of women's political participation in Brazil? And how will the female representation in the media of the country? To answer these questions, this article is a literature review of these topics, showing that, despite having a woman in the highest office of the Republic, women's political participation and their representation in the media is lagging behind.
\end{abstract}

\section{Key words}

Brazil; Politics; Women; women's political participation; Latin America.

\section{Introdução}

A participação política da mulher na América Latina por meio do voto é recente. O primeiro país latinoamericano que concedeu à mulher direito ao voto em eleições nacionais foi o Equador, em 1929. Três anos depois, em 1932, a conquista chega ao Brasil, seguido do Chile, onde as mulheres passaram a votar em
1934, da Bolívia em 1938, da Venezuela em 1946 e da Argentina, em 1947.

Muitas lutas foram travadas para uma maior representação política da mulher na região. O início do século XXI assistiu à chegada das primeiras mulheres eleitas a presidente em países latino-americanos por meio do 
voto direto. Hoje já são quatro as mulheres que assumiram ou assumem o mais alto posto Republicano entre os países da América Latina: Chile, Michelle Bachellet (2006 a 2010 e 2014 a 2017); Argentina, Cristina Kirchner (2007 a 2011 e 2011 a 2015); Costa Rica, Laura Chinchilla (2010 a 2014); e Brasil, Dilma Rousseff (2011 a 2015).

Embora as perspectivas sejam positivas em relação à participação política da mulher, muito ainda precisa ser feito no sentido do respeito aos seus direitos. Mulheres continuam sofrendo violência, abuso, preconceito e continuam a ser estereotipadas por uma sociedade que parece buscar mais por seus corpos do que por seus ideais.

Até mesmo as revistas destinadas ao público feminino, que poderiam desempenhar o papel de diminuir as diferenças entre homem e mulher, dando às suas leitoras informações relevantes na busca por seus direitos, acabam por colaborar "para a mitificação e a mistificação do ser feminino, ajudando a manter padrões" (BUITONI, 2009, p. 212).
Assim, este artigo tem como objetivos traçar um cenário da participação política feminina no Brasil e da representação das mulheres feitas pela mídia nacional, abordando alguns aspectos históricos, bem como a atual situação. Para tanto é feita uma revisão bibliográfica destes temas e uma pesquisa de dados nos portais do governo brasileiro.

$\mathrm{Na}$ primeira parte do artigo tratamos de apresentar a trajetória da mulher na política brasileira, apontando os momentos chave da participação feminina. Também apresentamos o cenário atual da representação política feminina, ressaltando o ineditismo da eleição de uma mulher ao cargo de presidente no país e questionando se este fato reflete a atual situação política da mulher brasileira.

Em seguida fazemos um resgate histórico da forma como a mulher foi representada pela mídia nacional a partir do século XIX. Este resgate se estende até as eleições presidenciais de 2010, que contou com duas mulheres na disputa e elegeu Dilma Rousseff a presidente.

\section{Trajetória política da mulher brasileira}

Falar sobre a trajetória política das mulheres brasileiras é tratar de conquistas de direitos, de espaço público para atuação. É também abordar as mudanças ocorridas na sociedade que fizeram com que a mulher deixasse de ter apenas o lar como palco de atuação e passasse a estar presente também nas escolas e universidades, no mercado de trabalho, nos mais variados tipos de associações e sindicatos, nos órgãos políticos em geral, enfim, em todas as instâncias sociais. É falar sobre luta, democracia, opressão, estereótipos, preconceitos, vitórias etc. Nosso trabalho não tem como objetivo detalhar toda esta trajetória, mas neste trecho faremos um breve resgate histórico sobre a participação política feminina no Brasil, para em seguida abordar de que forma a mulher tem sido representada na mídia.

De acordo com o Tribunal Superior Eleitoral (TSE),

A luta por esta conquista [de a mulher votar e ser votada] durou mais de 100 anos, pois o marco inicial das discussões parlamentares em torno do tema começou nos debates que antecederam a Constituição de 1824, a qual não trazia qualquer impedimento ao exercício dos direitos políticos por mulheres, mas, por outro lado, também não era explícita quanto à possibilidade desse exercício (TSE.JUS.BR, 2013).
Porém, as mulheres brasileiras não estavam sozinhas na luta pela igualdade de direitos perante uma sociedade patriarcal. Elas acompanhavam as tendências da Europa e dos Estados Unidos, onde se multiplicavam associações voluntárias com expressiva presença de mulheres. Todavia, a estrutura da sociedade patriarcal, na qual a mulher era hierarquicamente inferior ao homem, coibia as manifestações no Brasil (AVELAR, 2001: 18).

Como afirma Avelar, "[...] no início da década de 1920, as líderes do nascente movimento das sufragettes $^{1}$ mantinham ligações com as líderes do movimento internacional" (2001:18). Ainda de acordo com a autora, a Semana da Arte Moderna, de 1922, marcou um clima de mudança cultural mais favorável às pretensões femininas, porém, apenas para mulheres dotadas de riqueza e emancipação intelectual. Com isso, a luta pela inclusão das mulheres na política não significava uma mudança radical na época:

\footnotetext{
${ }^{1}$ Grosso modo, as sufragettes eram as mulheres que militavam pelo direito feminino ao voto.
} 
No geral, os movimentos urbanos dos anos 1920 e 1930 deixavam claro que as conquistas femininas não implicariam alterar a estrutura da sociedade e da família. Frutos da ação de mulheres de classe alta, os movimentos reiteravam a política conservadora da época (AVELAR, 2001: 19)

Os próprios jornais e revistas da época - assunto que será tratado mais detalhadamente adiante colaboravam para que as mulheres não aderissem ao "feminismo radical" presente em outros países e reiteravam que o lugar da mulher era no lar e não a arena política (AVELAR, 2001; BUITONI, 2009).

Em 1922 foi fundada a Federação Brasileira para o Progresso Feminino, que, filiada à International Woman Suffrage Alliance, impulsionaria o movimento pela conquista do voto feminino (AVELAR, 2000: 19).

Porém, antes mesmo de a mulher conquistar seu direito ao voto, foi eleita no Brasil a primeira prefeita, Alzira Soriano, na cidade de Lajes, Rio Grande do Norte (RN), em 1928. Esta eleição só foi possível com a aprovação da Lei $n^{\circ} 660$, de 25 de outubro de 1927, sancionada pelo então governador do RN José Augusto Bezerra de Medeiros que permitia o direito de a mulher votar e se eleger naquele estado - o que não era inconstitucional naquela época. Desta forma, Rio Grande do Norte foi o primeiro estado brasileiro a permitir o voto e a eleição feminina e Alzira a primeira prefeita da América Latina .Porém, a Comissão de Poderes do Senado anulou todos os votos femininos e interrompeu o mandato da prefeita, alegando a necessidade de uma lei especial a respeito (TSE.JUS.BR, 2013; AVELAR, 2001).

$\mathrm{O}$ direito da mulher ao voto em nível nacional se deu por meio do Decreto $\mathrm{n}^{\circ} 21.076$, de 24 de fevereiro de 1932, do então Presidente da República Getúlio Vargas, em resposta ao Código Eleitoral de 1932, que em seu artigo $2^{\circ}$ afirmava: "É eleitor o cidadão maior de 21 anos, sem distinção de sexo, alistado na forma deste Código". Contudo, somente dois anos depois, em 1934, com a inauguração de um novo Estado Democrático de Direito, por meio da segunda Constituição da República, esses direitos políticos conferidos às mulheres foram assentados em bases constitucionais. No entanto, a nova Constituição restringiu a votação feminina às mulheres que exerciam função pública remunerada (TSE.JUS.BR, 2013). Ainda assim, apenas em 1946 as mulheres votariam efetivamente, já que, durante o período que ficou conhecido como a ditadura de Getúlio Vargas, esse direito foi diluído, uma vez que nele as liberdades constitucionais, como o direito ao voto, foram suspensas (AVELAR, 2001: 20). O artigo 131 da Constituição de 1946 assegurava à mulher, bem como a qualquer outro cidadão maior de 18 anos, este direito: "São eleitores os brasileiros maiores de 18 anos que se alistarem na forma da lei" (TSE.JUS.BR, 2013).

Já a primeira mulher eleita para o cargo de governadora de um estado brasileiro foi Roseana Sarney, em 1994, no Maranhão - aqui vale observar o intervalo de 66 anos entre a primeira prefeita e a primeira governadora eleita, bem como o sobrenome Sarney, importante no contexto que elegeu Roseana como governante. E a primeira mulher eleita a presidente, foi Dilma Rousseff, em 2010.

Outra conquista feminina no âmbito da política foi a adoção de cotas para a candidatura de mulheres nos partidos políticos. Esta medida é uma ação afirmativa que busca criar condições para o estabelecimento de um maior equilíbrio entre homens e mulheres no plano da representação política. "Num primeiro momento, são medidas compensatórias que possibilitam que mais mulheres ocupem espaços. Num segundo, são medidas distributivas que buscam assegurar a igualdade entre homens e mulheres", avaliam Grossi e Miguel (2001: 169).

Criada em 1995, a Lei no 9.100, determinou que, no mínimo, 20\% das vagas de cada partido fossem destinadas a candidatas mulheres nas eleições municipais de 1996. Em 1997, com a Lei no 9.504, esse percentual mínimo aumentou para $25 \%$ para as eleições de 1998, incluindo mais cargos eleitos por voto proporcional (Câmara dos Deputados, Assembleias Legislativas Estaduais e Câmara Distrital), e 30\% para as posteriores (AVELAR, 2001: 80; GROSSI; MIGUEL, 2001: 169; TSE.JUS.BR, 2013). Foi ainda estabelecido que cada partido tenha uma cota mínima de 30\% e máxima de $70 \%$ para cada um dos sexos (GROSSI; MIGUEL, 2001: 169).

Porém, nem sempre as cotas são bem avaliadas. Como afirma Htun (2001: 227), em um texto que analisa a eficiência da adoção de cotas em onze países latino-americanos, "[...] a natureza do sistema 
eleitoral de cada país afeta significativamente o sucesso das políticas de cotas”. E a mesma autora avalia:

O ponto central da questão é que onze países aprovaram leis estabelecendo cotas. Entretanto, a presença feminina nos parlamentos alcançou o nível das cotas em apenas dois deles: na Argentina, em sua Câmara de Deputados, e no Paraguai, no seu Senado. Este fato mostra que a maioria das instituições eleitorais prejudica a eficácia da lei de cotas e muitos partidos políticos da região não estão comprometidos com ela (HTUN, 2001: 229).

No Brasil, Htun afirma que as cotas são prejudicadas, pelas seguintes razões:

Em primeiro lugar, a lista aberta gera uma competição no interior do partido. Em segundo lugar, a cota no Brasil não é obrigatória. Ou seja, a lei diz que os partidos têm que reservar $30 \%$ das vagas para as candidaturas femininas, mas os partidos não têm de preencher essas vagas com mulheres. Quer dizer, o partido pode sair com uma lista com menos candidatos e sem nada de mulheres (2001: 230).

Sobre lista aberta e lista fechada, cabe dizer que num sistema partidário de lista aberta, como no Brasil, "[...] os eleitores escolhem os seus candidatos votando nestes e não nos partidos” (HTUN, 2001: 227); já num sistema fechado "os eleitores votam nos partidos e não nos candidatos", e nele "[...] cada partido controla o posicionamento dos seus candidatos. A quantidade de votos recebida por partido determina quantos candidatos da lista serão eleitos" (HTUN, 2001: 227). Desta forma, no sistema aberto os candidatos de um mesmo partido concorrem entre si, enquanto no sistema fechado, quanto mais votos o partido obtiver, melhor para todos os candidatos, porém, é preciso que as mulheres estejam bem posicionadas nas listas fechadas para que possam ser eleitas.

Outra crítica feita às cotas é a de que junto com elas “[..] os parlamentares aprovaram um aumento no número total de candidaturas que os partidos poderiam apresentar nos pleitos eleitorais, o que, na prática, resultou em uma diminuição do impacto da medida aprovada” (GROSSI; MIGUEL, 2001: 169).

A Lei das cotas foi impulsionada por uma série de ações, como a Campanha Nacional Mulher sem Medo do Poder (1996), que sucedeu a IV Conferência Mundial sobre a Mulher (ONU, 1995) em Pequim, na China. Esta Conferência tornou-se um marco na luta das mulheres pelos direitos políticos e de cidadania. De acordo com ROCHA (2012: 15):

A Plataforma de Ação da Conferência, em um de seus objetivos estratégicos afirma ser necessário "Adotar medidas para garantir às mulheres igualdade de acesso às estruturas de poder e ao processo de decisão e sua participação em ambos". E que os governos devem adotar: "medidas, inclusive quando apropriado, nos sistemas eleitorais, para estimular os partidos políticos a incorporarem as mulheres a postos públicos eletivos e não eletivos, na mesma proporção e nas mesmas categorias que os homens" e devem também "examinar o impacto dos sistemas eleitorais sobre a representação política das mulheres nos organismos eletivos e considerar, quando procedente, a possibilidade de ajustar ou reformar esses sistemas".

Após a Conferência, vários outros espaços foram criados ou reforçados no Brasil e no mundo para discutir a situação da mulher, como os três abaixo.

O Seminário Mulheres na Política - Mulheres no Poder, organizado pelo Centro Feminista de Estudos e Assessoria Cfemea (Cfmea), pela Bancada Feminina no Congresso e pelo Conselho Nacional dos Direitos da Mulher (CNDM), em maio de 2000, é um dos exemplos. Nele, as principais temáticas propostas foram: "[...] a participação política das mulheres, a validade das cotas e a questão do poder" (GROSSI; MIGUEL, 2001: 170).

Já em agosto de 2007, a II Conferência Nacional de Políticas para as Mulheres, aprovou o II Plano Nacional de Políticas para as Mulheres, incluindo o eixo Participação das Mulheres nos Espaços de Poder e Decisão, com o objetivo de "promover e fortalecer a participação igualitária, plural e multirracial das mulheres nos espaços de poder e decisão", tendo como uma das metas revisar a lei de cotas eleitorais.

Em 2009 houve a chamada "minirreforma eleitoral" (Lei 12.034/2009), com a qual os partidos passaram a destinar 5\% do Fundo Partidário para a formação política das mulheres, devendo $10 \%$ do programa do partido ser destinado às mulheres. Outro ganho significativo na lei foi a mudança no texto: de "deverá reservar" para "preencherá o mínimo de 30\% e o máximo de $70 \%$ para candidaturas de cada sexo" (ROCHA, 2012: 16).

Todas essas conquistas contribuíram para melhorar a representação política feminina no Brasil, mas a mulher continua numa condição de sub-representação 
quando nos deparamos com o restante da realidade social, como observou Rocha (2012: 15):

\begin{abstract}
As mulheres representam $51 \%$ da população brasileira; tem um nível de escolaridade superior ao dos homens e já se observa uma queda no índice de analfabetismo; estão próximo de alcançar os $50 \%$ da população economicamente ativa, mas ainda recebem $70 \%$ do salário dos homens. Elas chefiam $1 / 3$ das famílias brasileiras e a média de filhos é de 1,8. Apesar da Lei Maria da Penha, o nível de violência é inaceitável. Após 78 anos da conquista do voto, as mulheres, no momento atual, representam a maioria do colégio eleitoral brasileiro.
\end{abstract}

Entre os fatores que dificultam uma maior participação feminina nas instâncias do poder, Grossi e Miguel citam a ideia de que o espaço de atuação da mulher é o lar e não a política; a dificuldade de conciliação entre a vida doméstica e a política; e a falta de apoio financeiro nas candidaturas (2001: 177181).

De acordo com Rocha, é preciso "[...] reverter este quadro da sub-representação, pois não é admissível a construção da verdadeira democracia sem a participação efetiva das mulheres nas esferas do poder" (ROCHA, 2012:15).

As declarações de Avelar (2001:9) vão ao encontro das observações de Rocha. De acordo com a primeira, “[...] a sub-representação social e política das mulheres são faces de uma mesma moeda. As mulheres têm status social mais baixo do que os homens, em decorrência de seu mais baixo status ocupacional". A autora ainda afirma que "[...] a subrepresentação das mulheres na política é a mesma da de outros grupos em condição de desigualdade nas condições de vida e na estrutura das oportunidades" (AVELAR, 2001: 30).
Por outro lado, características tidas como femininas têm sido valorizadas positivamente, como a sensibilidade. "[...] Parece haver unanimidade na afirmação de que as mulheres são mais 'sensíveis' ao social” (GROSSI; MIGUEL, 2001:193), sendo, portanto, diferente o modo de fazer política da mulher em relação à política feita pelo homem. É atribuído também à mulher, muitas vezes, um valor ético, que a elas seria intrínseco: "Nesse entendimento, uma maior presença das mulheres nos espaços de poder resolveria, por si só, uma equação que associa poder = homem = corrupção" (GROSSI; MIGUEL, 2001: 178).

Porém, a efetiva participação política, social e econômica funciona ainda como uma espécie de termômetro de uma democracia, já que a ideia de todos os cidadãos participarem na vida política está incutida na própria ideia de democracia, como afirma AVELAR (2004: 234),

Só resulta em democratização quando a participação se materializa em políticas para efetiva extensão de direitos e que a cada nova classe de direitos alcançados corresponda à efetiva integração de cada membro com igual valor na coletividade política.

Assim, embora o Brasil já tenha avançado bastante neste sentido, ainda há muito para ser feito para uma democracia plena, tanto em igualdade na participação política entre diferentes perfis sociais, seja em relação a gênero, orientação sexual, condições financeiras como poderá ser visto no tópico a seguir -, quanto em garantia aos direitos de cidadania a toda população.

\section{Cenário atual da participação política feminina brasileira}

"Meus queridos brasileiros e brasileiras. Pela decisão soberana, do povo, hoje será a primeira vez que a faixa presidencial cingirá o ombro de uma mulher", foram as primeiras palavras de Dilma Vana Rousseff em seu discurso de posse presidencial, em $1^{\circ}$ de janeiro de 2011, no Congresso Nacional. A presidente ainda declarou que para assumir o cargo teria consigo "a força e o exemplo da mulher brasileira". Mais adiante, afirmou: "Venho para abrir portas para que muitas mulheres também possam no futuro ser presidentas. E para que no dia de hoje todas as mulheres brasileiras sintam orgulho e alegria de ser mulher". E ainda nos minutos iniciais do discurso, declarou: "Meu compromisso supremo é honrar as mulheres, proteger os mais frágeis e governar para todos.” (BRASIL, 2013).

No decorrer do discurso de posse, Dilma Rousseff falou sobre seu compromisso, os desafios, o estado 
atual da política e da economia do país, os planos e sobre sua trajetória política, entre outros assuntos. Mas de suas primeiras palavras podemos destacar o ineditismo de uma mulher ser eleita a presidente no país. Porém, será que o fato de termos uma mulher na presidência reflete a realidade da participação política feminina no Brasil?

Um ranking feito com 146 países pela InterParliamentary Union (IPU), em 2011, pode nos ajudar a responder a esta pergunta, pois mostra que Dilma Rousseff faz parte de uma minoria feminina a ocupar um cargo político no Brasil:

Embora sejam inegáveis a força e a importância das mulheres no cenário socioeconômico e cultural brasileiro, o país ocupa uma posição vergonhosa no ranking mundial relativo à participação de mulheres no Parlamento, figurando em $109^{\circ}$ lugar, com menos de $9 \%$ de presença feminina (IPU.ORG, 2011), muito atrás de países como Costa Rica e Argentina, que estão em $11^{\circ}$ e $12^{\circ}$ lugares, respectivamente (SANEMATSU; MELO, 2012: 484).

Em abril de 2013, os dados da IPU colocam o Brasil na $123^{\mathrm{a}}$ posição do ranking, com $8,6 \%$ de mulheres no poder, enquanto o Ruanda, o primeiro colocado, conta com 56,3\% de participação feminina nos cargos políticos (IPU.ORG, 2013).

Durante audiência pública da Comissão de Direitos Humanos e Legislação Participativa $(\mathrm{CDH})$, realizada em 21 de maio de 2013 em Brasília, a fala dos autores de um livro sobre a participação da mulher nas eleições de 2010 revelou que o país está em último lugar no que diz respeito à participação política feminina. "O Brasil tem menos de 10\% de mulheres na política, perdendo até para o Iraque e o Afeganistão. Para dividir paritariamente [os cargos políticos] com os homens, as mulheres vão levar quase 150 anos, já que o ritmo de crescimento é de $1 \%$ a cada eleição", observou José Eustáquio Diniz (SENADO, 2013).

Para os defensores de uma maior participação da mulher na política, os números são desanimadores: das 15. 102 candidaturas ao cargo de prefeito nas eleições de 2012, apenas 2.022 foram protagonizadas por mulheres, ficando os homens com 13.080 vagas. Destas, 665 mulheres foram eleitas a prefeitas em seus municípios; já o número de homens eleitos foi de 4.994, o que representa pouco mais de $88 \%$ das 5.609 prefeituras do país comandadas por homens
(Tabela 1). Ainda nas eleições de 2012, 134.008 mulheres se candidataram a vereadoras, sendo 7.639 eleitas; o número de homens que se candidataram ao mesmo cargo foi de 286.088, com 49.698 eleitos (Tabela 1) (TSE.JUS.BR, 2013).

Nas eleições de 2010, quando a presidente Dilma Rousseff foi eleita, eram sete homens e duas mulheres disputando a presidência. Dos 27 estados da federação, 13 não tiveram nenhuma mulher candidata ao cargo de governador naquele ano; das 16 candidatas, duas assumiram o cargo, sendo os outros 25 estados governados por homens (Tabela 1) (TSE.JUS.BR, 2013).

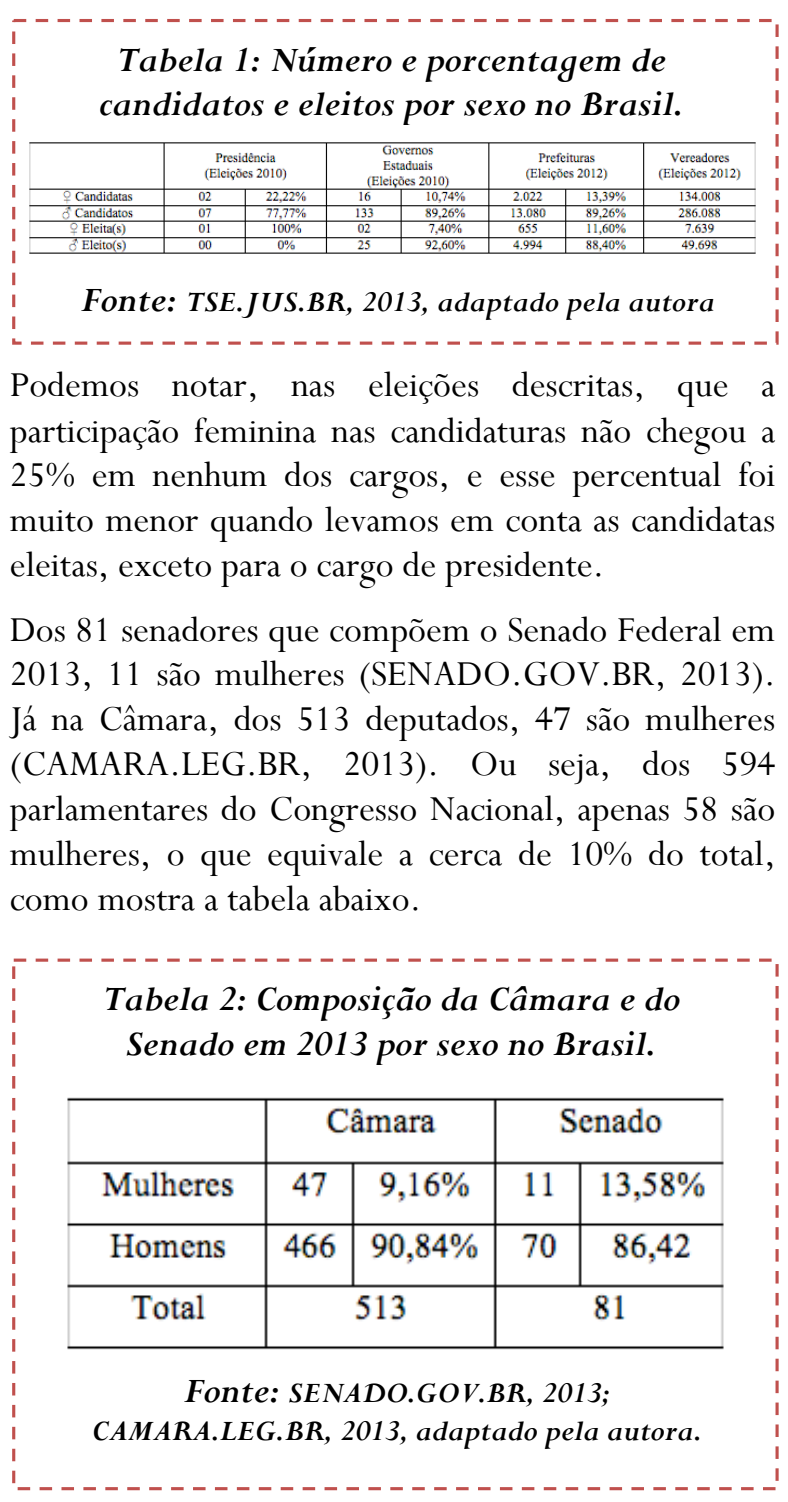


Embora a participação política feminina, no âmbito de candidaturas e candidatas eleitas, seja muito menor em relação à masculina, os números apontam crescimento, como mostram os dados a seguir.

A análise do Centro Feminista de Estudos e Assessoria (Cfemea) em relação às eleições de 2000, 2004 e 2008 para prefeitos e vereadores, revela que:

Em 2000, as mulheres candidatas à vereadora somaram 70.321, sendo eleitas 7.001, o que representa 9,95\% das candidatas. Nesse mesmo ano, as mulheres candidatas à prefeita somaram 1.139, sendo eleitas 317 , o que representa $27,83 \%$.

Nas eleições de 2004, as mulheres candidatas a vereadora somaram 76.762, sendo eleitas 6.555, o que representa $8,53 \%$ das candidatas. Nas eleições para prefeita, as mulheres candidatas somaram 1.494, sendo eleitas 407, representando $27,24 \%$.

Finalmente, nessas eleições de 2008, as mulheres candidatas a vereadora somaram 69.341, sendo eleitas 6.512, o que representa 9,39\% das candidatas. Nas eleições para prefeita, as mulheres candidatas somaram 1.641, sendo eleitas 505, representando 30,77\% (CFMEA.ORG.BR,2013)

Nas três eleições observadas pelo Cfema, houve um aumento nas candidaturas e vitórias femininas no cargo de prefeita, mas uma diminuição nos cargos de vereadora. Porém, se compararmos estes números com os das eleições de 2012, veremos que mais mulheres se candidataram e se elegeram para ambos os cargos.

Sobre o crescimento nas prefeituras e diminuição nas câmaras de vereadores, a análise do Cfemea (2013), diz:

Esse fenômeno de ampliação das posições femininas como prefeitas e diminuição das mesmas como vereadoras aponta para um problema de aplicação e para a falta de eficácia das cotas de $30 \%$ para as mulheres nas listas de candidaturas. O sistema de cotas parece possuir, portanto, um caráter mais simbólico do que efetivo e influencia indiretamente a disputa pelo cargo de prefeito/a e estimula o debate acerca da necessidade de ampliação da participação política das mulheres para o aprofundamento da democracia.

Vejamos mais alguns dados sobre o número de mulheres eleitas nos cargos executivos, cujo o voto se dá pelo princípio majoritário, nas últimas eleições no país:
Tabela 3: Número de mulheres eleitas a prefeitas de 1976 a 2012 no Brasil

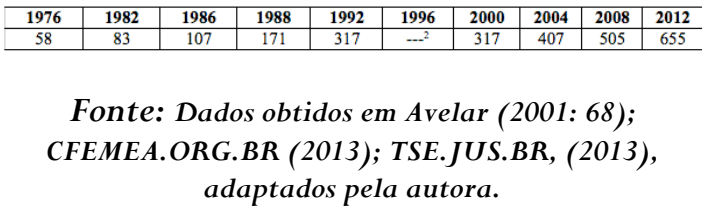

Fonte: Dados obtidos em Avelar (2001: 68);

CFEMEA.ORG.BR (2013); TSE.JUS.BR, (2013), adaptados pela autora.

Tabela 4: Número de mulheres eleitas a governadoras de 1994 a $2010^{3}$

\begin{tabular}{|c|c|c|c|c|}
\hline $\mathbf{1 9 9 4}$ & $\mathbf{1 9 9 8}$ & $\mathbf{2 0 0 2}$ & $\mathbf{2 0 0 6}$ & $\mathbf{2 0 1 0}$ \\
\hline 01 & 01 & 02 & 03 & 02 \\
\hline
\end{tabular}

Fonte: Dados obtidos em TSE.IUS.BR (2013)

Apesar do crescimento observado, as mulheres ainda são minoria nas candidaturas e nos cargos políticos brasileiros. É válido ressaltar que o Brasil tem hoje 5570 municípios e 27 unidades federativas, composta por 26 estados mais o distrito federal. Assim, nas últimas eleições, as mulheres assumiram apenas cerca de $12 \%$ das prefeituras e $7,4 \%$ dos governos estaduais e distrital.

No que diz respeito à Presidência da República, 2010 foi a primeira vez que uma mulher ganhou as eleições para este posto no Brasil. A primeira candidatura para este cargo aconteceu em 1998, quando Thereza Ruiz, candidata do PTN (Partido Trabalhista Nacional), concorreu com outros onze candidatos (GROSSI; MIGUEL, 2001: 170).

Por outro lado, o contingente do eleitorado é bem semelhante entre homens e mulheres, sendo que elas são a maioria: 51,9\% dos eleitores que estavam no Brasil e $60,6 \%$ dos que se encontravam no exterior em 2012 eram mulheres (TSE.JUS.BR, 2013).

\footnotetext{
2 Não conseguimos localizar os dados das eleições municipais de 1996 categorizados por gênero.

${ }^{3}$ Usaremos os dados apenas das últimas cinco eleições porque antes de 1994 as eleições estaduais não obedeciam, necessariamente, o mesmo calendário em todo o país, e foi a partir de 1994 que ela passou a se fazer junto com as eleições presidenciais e ao mesmo tempo para o país todo.
} 


\section{A mulher na mídia}

Entendendo a mídia como um espaço onde são criadas formas de sociabilidade, faremos um resgate histórico de como a mulher foi representada por uma mídia criada para o público feminino. Abrangendo, assim, ao mesmo tempo, como a mulher foi representada em uma mídia a ela dedicada e como esta mulher consumidora de mídia foi incentivada por sua leitura a se enxergar e a se comportar.

A pesquisadora Dulcília Buitoni, na segunda edição de seu livro Mulher de Papel: a representação da mulher pela imprensa feminina brasileira faz uma análise das publicações dos séculos XIX e XX, dirigidas ao público feminino, na busca das representações feitas pela mídia das mulheres brasileiras.

De acordo com a autora "[...] a relação entre a imprensa feminina e a mulher implica questões mais abrangentes, como o papel social da mulher ou sua participação política. E aí entra a ideologia” (2009:21). Ou seja, essas publicações dirigidas à mulher podem influenciar também seu modo de se enxergar e se posicionar na sociedade, mas essas mesmas publicações são carregadas de ideologia.

Assim, a história da imprensa feminina se desenvolve em dois planos, sendo o primeiro o dos “deveres”, no qual se encaixam publicações sobre estilos, modas e convenções, as quais "ajudavam as mulheres a viver da maneira que os homens queriam que elas vivessem" (SULLEROT, 1963: 79, Apud BUITONI, 2009: 187); e o segundo plano é o dos "direitos", no qual estão periódicos que abordam "a condição feminina”, sendo denominados de "feministas" por Sullelot (BUITONI, 2009: 187).

Sullelot fez um longo estudo sobre a imprensa feminina francesa, descobrindo que o perfil de leitora visada pelas publicações mudou ao longo dos anos. De acordo com ela, "existem três fases na imprensa feminina francesa que passou sucessivamente pela dama, pela mulher e pela dona de casa consumidora" (SULLEROT, 1963: 15, Apud BUITONI, 2009: 187-188). Cronologicamente, o século XVIII foi o das “damas", o XIX da "mulher" e a partir do século
$\mathrm{XX}$, a mulher se transformaria em "dona de casa consumidora” (BUITONI, 2009: 188-189).

No Brasil, a imprensa feminina também passou da "senhora à mulher e depois à consumidora", conforme afirma BUITONI (2009: 189), porém com uma ordem cronológica diferente, uma vez que "[...] não tivemos imprensa feminina (ou qualquer outra imprensa) no século XVIII. A imprensa feminina no Brasil começou por volta de 1820, com publicações de moda e literatura [...]" (BUITONI, 2009: 189).

Ainda sobre o tratamento dispensado às leitoras pelas revistas femininas, Buitoni afirma: "Vós, tu, você: o texto na imprensa feminina sempre vai procurar dirigir-se à leitora como se estivesse conversando com ela, servindo-se de uma intimidade de amiga” (2009: 191). Porém, pondera que "[...] esse jeito coloquial, que elimina a distância, que faz as ideias parecerem simples, cotidianas, frutos do bom senso, ajuda a passar conceitos, cristalizar opiniões, tudo de um modo tão natural que praticamente não há defesa”, uma vez que "a razão não se arma para uma conversa de amiga” (2009: 191). Ou seja, tratando a leitora como amiga, as publicações femininas incutem sua ideologia de forma sorrateira.

Historicamente, a imprensa feminina surge no Brasil com a chegada da corte portuguesa ao Rio de Janeiro, que se tornava uma capital em contato com o mundo, em detrimento de seu caráter provinciano. Isso passou a "[...] influir na vida da mulher do Rio de Janeiro, exigindo-lhe mais participação” (BUITONI, 2009: 31). Buitoni relaciona a instalação da corte na capital carioca com a importância que a moda assumiu para a mulher e a criação de um mercado consumidor de uma mídia que trataria de moda:

Dentro deste contexto, a moda assumiu grande importância para a mulher que morava nas cidades, ainda mais se fosse na corte. As tendências europeias eram copiadas e aí entra o fator imprensa, primeiro com a importação de figurinos vindos de fora e depois com a publicação, aqui, de jornais e revistas que reproduziam gravuras de moda. A necessidade estava criada; havia, portanto, um mercado. Foi por isso que as primeiras publicações dirigidas à mulher, no Brasil, traziam moda. 
Jornalismo feminino, nessa época, significava basicamente moda e literatura (BUITONI, 2009: 31-32).

Outras características marcantes da imprensa feminina observadas por Buitoni são: “[...] os assuntos (ou editorias) predominantes e o desprezo pela atualidade" (2009: 24). A autora argumenta que ambas acentuam "o seu [da mulher] desligamento com o mundo real” (2009: 25), já que os assuntos permeiam por temas como culinária, moda, beleza, literatura, comportamento e que se distanciam dos fatos cotidianos.

Após pesquisar dezenas de títulos publicados no país, no século XIX, e escolher dentro destes periódicos alguns textos para analisar, a autora considera que houve duas formas de representação da mulher predominantes na mídia brasileira naquele período: "[...] a tradicional, que não permite liberdade de ação fora do lar e que engrandece as virtudes domésticas e as qualidades 'femininas'; e a progressista, que defende os direitos das mulheres, dando ênfase à educação" (BUITONI, 2009: 47).

Buitoni considera que "[...] na imprensa feminina, a mulher está, metafórica e metonimicamente, ligada aos seus papeis sociais básicos: dona de casa, esposa, mãe, principalmente até os anos 1970" (2009: 200). A partir dos anos 1960, afirma a autora "[...] aparecia uma tendência que privilegiava a consumidora. E mais do que mãe ou esposa, o status de namorada foi se fortalecendo" (BUITONI, 2009: 200).

Em sua análise, Buitoni mostrou diversas representações de mulher, que foi de o ser mais belo e puro do mundo à pessoa sexy que sugere o uso da camisinha, e conclui que a imprensa feminina não mudou muito ao longo do tempo no que diz respeito à representação feminina, sendo a mulher, representada pelos papeis que é colocada a cumprir na sociedade:

De papel em papel a imprensa feminina colabora para a mitificação e a mistificação do ser feminino, ajudando a manter padrões. [...] Dos papeis usados para impressão aos papeis atribuídos à mulher, chega-se ao papel da imprensa feminina - diluir os conflitos sociais. [...] Rasgar o papel e descobrir a pessoa: veremos um dia? (2009: 212).
Por outro lado temos as publicações feministas, que, engajadas nos temas e lutas das mulheres, fazem contraponto às revistas femininas comerciais. Sobre essas publicações, Elizabeth Cardoso (2004), que pesquisou sobre a imprensa feminista pós-1974, considera que esta esteve muito relacionada com a imprensa alternativa, da década de 70, mas que continuou a existir nos anos 1980, 1990 e início dos anos 2000 (anos de abrangência de sua pesquisa), mesmo com o enfraquecimento do jornalismo alternativo. Prova disso foram os 75 títulos de periódicos feministas que a autora encontrou ao realizar sua pesquisa (2004: 37). Diante deste corpus, a autora considerou que as revistas feministas podem ser classificadas em dois grupos: a primeira geração, voltada para as questões de classe e a segunda geração, voltada para as questões de gênero.

Em linhas gerais, porém, foi possível traçar características das publicações da primeira geração e características das publicações da segunda geração. Notase que, enquanto a primeira está marcada pelo debate entre "questão da mulher" versus "questão geral", feminismo liberal versus feminismo marxista ortodoxo, por reivindicações de ações públicas que coloquem as mulheres em igualdade com homens, pela questão da autonomia partidária e pelo combate à ditadura, já a segunda geração da imprensa feminista incorpora o conceito de gênero, assume os temas relacionados direta e exclusivamente às mulheres (como sexualidade, planejamento familiar e violência contra a mulher); tende para a especialização por temas; luta pelo direito à diferença e opera em parceria com um novo ator social, a sociedade civil organizada, na forma de ONGs e associações voltadas para a questão de gênero (CARDOSO, 2004: 38).

Assim, as publicações feministas não apenas apresentavam outras representações da mulher, mas também colocavam em pauta assuntos que visavam o empoderamento feminino. Porém, o acesso às revistas comerciais é bem maior do que às publicações femininas, muitas vezes produzidas no âmbito dos movimentos sociais e nos grupos acadêmicos, o que faz com que a chamada 'grande mídia', tenha mais influência na vida da maioria das mulheres, sendo, portanto, a forma escolhida de mídia para analisar a representação da mulher na política nos dias de hoje. 


\section{A política feminina na mídia}

Vimos que histórica e culturalmente foi negado à mulher o direito à participação política, já que sua atuação estaria restrita à esfera privada do lar, onde ela seria a rainha, dotada de características nem sempre atingíveis que a transformaria num mito, independente de tempo e espaço. Vimos ainda que a mídia ajudou na consolidação e na legitimação desta condição.

Será, portanto, que a imprensa, em algum momento, irá motivar a mulher a participar da política, exigir seus direitos? E no século XXI, no qual uma mulher é eleita a presidente do Brasil pela primeira vez, a imprensa faz que tipo de representação da mulher?

Buitoni recupera um texto publicado no número 425 da Revista Ilustrada (conhecida por uma postura mais de vanguarda), de 1886, que após defender o direito da mulher a mais espaço no mercado de trabalho, afirma, porém, que política não é espaço para mulher: "Na política, porém, o bello sexo só deve passar a vol d'oiseau, n'um âmbito largo, que lhe deixe ver os factos de longe. Nada de se intrometer em luctas eleitorales, de pedir votos, de formar comitês, de patrocinar candidatos" (BUITONI, 2009: 35). Este trecho é um bom representante da forma como à mulher era negado o direito de participação política no final do século XIX, bem como a legitimidade que a imprensa dava a este tratamento.

Já no século XX, pudemos notar, pelas representações femininas observadas e destacadas por Buitoni, que a política não era prioridade nas publicações femininas, bem como que estas não incentivavam o interesse político da mulher, público-alvo destas revistas. Porém, algumas vezes surgiam espaços para essa vertente, como quando Luiza Erundina, em 1988, foi eleita a primeira mulher prefeita da cidade de São Paulo, e a revista Capricho publicou uma crônica, do jornalista Nirlando Beirão, intitulada "Dona Luiza vence no país masculino” (BUITONI, 2009: 131).

Uma das hipóteses para essa quase invisibilidade da representação política feminina na mídia, configurada por Luís Felipe Miguel e Flávia Biroli (2008), é a de que "[...] o âmbito considerado "próprio" para a política feminina - questões sociais, família, assistência social, meio-ambiente etc. - é também aquele que menos impulsiona as carreiras políticas e que possui menor visibilidade na cobertura jornalística da política” (p. 24). Para testar esta hipótese, os autores analisaram, entre os anos de 2006 e 2007, os telejornais Jornal da Band, Jornal do SBT e Jornal Nacional e as revistas semanais Veja, Época e Carta Capital (MIGUEL; BIROLI: 25).

A partir da análise eles puderam observar "[...] uma presença reduzida das mulheres em relação aos homens, permitindo observar assimetrias de gênero nas representações do mundo social e, em especial, nas representações da política difundidas pela mídia” (MIGUEL; BIROLI, 2008: 38). Para os autores, isso se dá em função de que os meios de comunicação de massa só dão espaço no noticiário político “[...] aqueles que estão investidos em cargos públicos, sejam eles eletivos ou de confiança”, sendo que "[...] aos outros - categoria que inclui os próprios espectadores - cabe acompanhar o jogo" (MIGUEL; BIROLI, 2008: 38). Assim,

A sobrevivência de estereótipos de gênero constrange sua ação política e a visibilidade desta ação no noticiário jornalístico, num processo que se realimenta. Isto é, o âmbito considerado "próprio" para a política feminina é também aquele que menos impulsiona as carreiras políticas e que possui menor visibilidade na cobertura jornalística da política (MIGUEL; BIROLI, 2008: 24).

Em 2010 a candidatura e posterior eleição de Dilma Rousseff à presidência do Brasil alavancariam pautas na mídia sobre a questão da mulher na política. Diante disso, Leila Barbara e Maria Carmen Aires Gomes (2010) fizeram uma análise sobre a representação de Dilma Rousseff nas revistas Veja, Época e Isto é em dois momentos: de 2003 a 2006, em que Dilma era Ministra das Minas e Energia e, depois, da Casa Civil, durante o Governo Lula; e entre 2006 e 2009, abrangendo desde sua atuação como Ministra da Casa Civil à sua configuração como candidata à presidente (2010: 74).

Da análise feita pelas autoras, é notável a relação estabelecida entre as tais características tidas como femininas, citadas por Buitoni, e a imagem de Dilma. Afirmam as autoras, ao observar a fase de 
Dilma enquanto Ministra que: "Sensibilidade, ternura, emoção, pureza não surgem como atributos e qualificadores da 'natureza' feminina de Dilma Rousseff-ministra, mas sim traços de rispidez, austeridade e agressividade, caracterizando uma imagem de sujeito-políticomulher, com potencialidades masculinas" (BARBARA; GOMES, 2010: 76).

Dilma, de acordo com as autoras, passou por um processo de transformação em sua aparência e postura, inclusive por um procedimento cirúrgico estético, visando suavizar a imagem da candidata para a disputa presidencial, já que este cargo exigia uma figura mais humanizada:

Da representação do combatente emerge a figura da docilidade, uma tentativa do modelo normativo de humanizar a militante-guerrilheira, nada disso obscurece o fato de ser mais uma estratégia manipulativa, para atingir determinados fins no processo eleitoral. De maneira geral, não podemos ignorar que este deslocamento gera um efeito cultural inverso: figura feminina, construída sócio-culturalmente, com traços masculinizados passa por uma transformação que a torna mulher-sujeito-política com traços + feminino, emotivo e sentimental (BARBARA; GOMES, 2010: 88).

Porém, Dilma Rousseff rompia, de acordo com as autoras, com o modelo de mulher proposto pelas teorias binárias, as quais existem características unicamente femininas e outras masculinas, e se configurou, inclusive por sua militância na guerrilha, como um sujeito-político-mulher, o que, pela mídia, foi bastante explorado:

Os resultados apontam ainda que os veículos midiáticos analisados constroem representações hegemônicas sobre Dilma Rousseff, pelo fato de ela não ter atributos e características do que seja uma "mulher tradicional, conservadora, aquela que atende ao modelo binário, biológico", mas dura, com tom firme, comportamento inflexível (BARBARA; GOMES; 2010: 39).

A eleição de 2010, que além de Dilma Rousseff contou com a candidatura de Marina Silva à presidência, também foi objeto de estudo de Marina Sanematsu e Jacira Vieira de Melo (2012), que monitoraram a cobertura jornalística de 29 jornais impressos diários, quatro revistas semanais e quatro telejornais, de julho a outubro de 2010, sobre as eleições para cargos majoritários, a partir da perspectiva da participação das mulheres no processo eleitoral, como candidatas, como eleitoras e como foco dos programas de governo e plataformas eleitorais apresentadas pelas candidaturas (SANEMATSU; MELO, 2012: 479480).

A investigação das autoras mostrou que "[...] a presença de duas mulheres com grande força eleitoral na campanha presidencial de 2010 foi o fator que mais contribuiu para que o tema mulheres na política recebesse atenção na cobertura da imprensa" (SANEMATSU; MELO, 2012: 480).

Destacam ainda que "[...] a cobertura sobre mulheres na política deu-se em torno de dois focos principais: as candidaturas femininas e a agenda de interesse das mulheres" (SANEMATSU; MELO, 2012: 497). Sendo que, "[...] no primeiro caso, estão contabilizadas as matérias que discutiam as candidaturas, tendo em vista a condição feminina das postulantes aos cargos. No segundo, estão os textos sobre algumas das questões que atingem diretamente a vida das mulheres brasileiras" (SANEMATSU; MELO, 2012: 497).

Entre os resultados apontados por Sanematsu e Melo, nos chamou atenção as seguintes constatações:

a) A pouca atenção à sub-representação política feminina: "Menos de 10\% dos textos analisados chama atenção para a proporção entre homens e mulheres no acesso e participação em espaços de poder e decisão" (2012: 511);

b) A corroboração da ideia, que vimos anteriormente, de que uma política praticada pelas mulheres traria mais ganhos do que perdas, por elas serem socialmente mais justas, apareceu quando o questionamento sobre ganhos e perdas da maior participação política feminina entrou em pauta: "A maioria dos textos que mencionam ganhos aponta maior atenção/sensibilidade para as questões sociais e maior competência caso as mulheres possuíssem maior destaque no cenário político" (2012: 512);

c) A forte ligação da imagem da mulher à família: "A maior parte das representações refere-se às mulheres candidatas como ligadas à família, no papel de mãe, filha, esposa, avó, etc" (2012: 512); 
d) Maior exposição da vida privada feminina do que masculina: "Cabe destacar que as representações na mídia sobre as eleitoras e as candidatas foram em geral positivas, embora as candidaturas femininas sejam apresentadas de forma um pouco mais rigorosa e estereotipada que as masculinas, tendo sido mais expostos aspectos das vidas privadas das mulheres, em especial vínculos familiares e questões relacionadas à aparência, como peso, cabelo, maquiagem e vestimentas" (2012: 481).

Assim, diante do corpus estudado, as autoras consideraram a atuação da mídia fraca, ou, nas palavras delas:

A cobertura sobre mulheres na política no período eleitoral foi superficial, mais factual do que analítica e pouco investigativa. A imprensa analisada - impressa e televisiva - não aproveitou a oportunidade apresentada por um momento inédito na política brasileira, em que as mulheres - como candidatas e eleitoras - tiveram papel fundamental na definição dos rumos do país. Várias questões, a partir de ângulos diversos, poderiam ter sido pautadas. Mas faltou esforço investigativo. Por desinformação, preconceito ou desinteresse, nas eleições de 2010 o jornalismo brasileiro ficou devendo, não apenas às mulheres brasileiras, mas ao fortalecimento da democracia no país (SANEMATSU; MELO, 2012: 515).

O que foi percebido com essas análises sobre a representação da mulher na mídia, desde Buitoni ao estudo de Sanematsu e Melo é que a visão estereotipada da mulher, herdada historicamente e fortalecida até então, pela cultura e pela mídia, está presente em todas as representações femininas feitas pelos meios de comunicação, seja na forma como uma revista feminina tenta encaixar a adolescente que responde a um teste num modelo pré-estabelecido ou na necessidade de suavizar a aparência de uma candidata à presidência do país.

Esta visão estereotipada, acreditamos, não reflete a realidade da mulher brasileira, que, apesar de toda violência e opressão, é chefe de família, gestora de empresas, professora universitária, líder de associação de bairro, atriz de sucesso internacional, presidente da República. Acreditamos ainda que esta representação diminua, mesmo que a passos lentos, conforme mais mulheres ocupem seus espaços no poder, seja ele político ou não.

\section{Considerações finais}

Este artigo se propôs a fazer um resgate bibliográfico sobre a participação da mulher na política brasileira e sua representação na mídia.

Revisitando autores que abordaram estas temáticas, mostrou que, apesar de o Brasil ter uma mulher como presidente, ainda há muito que se fazer para que as mulheres alcancem uma posição de igualdade perante os homens nos espaços de poder. Porém, os números têm mostrado um aumento lento e gradual nesta participação.

No que diz respeito à representação feminina na mídia brasileira, pudemos notar que a mulher nunca foi personagem ou público para questões políticas, estando ela representada de maneira estereotipada, relacionada a conteúdos sobre tarefas domésticas, moda, beleza e sexualidade. Mesmo quando em 2010 duas mulheres disputaram, com sete homens, a presidência da República, a temática mulher na política figurou na mídia de forma superficial.

Diante disso, acreditamos que a participação política feminina e a representação da mulher na mídia são processos que acompanham o desenvolver da história do país, estando neste século XXI em um momento de mudança e evolução. Assim, torna-se importante conhecer e compreender a natureza do espaço ocupado pelas mulheres na mesma proporção e intensidade que analisamos, até agora, o desempenho de outros atores sociais. 


\section{Referencias}

- Avelar, L. (2001). Mulheres na elite política brasileira. São Paulo: Editora Unesp.

- Barbara, L. \& Gomes, M. C. A. (2010). A representação de Dilma Rousseff pela mídia impressa brasileira: analisando os processos verbais. Revista Letras. vol. 20 (40), pp. 67-92. Recuperado el día 26 de marzo de 2013 de http://w3.ufsm.br/revistaletras/artigos_r40/artig o_04.pdf.

- Brasil.gov.br. (2013). Leia íntegra do discurso de posse de Dilma Rousseff no Congresso. Recuperado el día 20 de marzo de 2013 de http:/ /www.brasil.gov.br/governo/2011/01/leia -integra-do-discurso-de-posse-de-dilma-rousseffno-congresso.

- Buitoni, D. H. S. (2009). Mulher de Papel: a representação da mulher pela imprensa feminina brasileira. São Paulo: Summus.

- Grossi, M. P. \& MIGUEL, S. M. (2001). Transformando a diferença: as mulheres na política. Revista Estudos Feministas. vol. 9 (1), pp. 167-195.

- Htun, M. (2001). A política de cotas na América Latina. Revista Estudos Feministas. vol. 9 (1), pp. $225-230$

- Ipu.org. (2013). Women in national parliaments. Recuperado el día 4 de abril de 2013 de http://www.ipu.org/wmn-e/classif.htm.
- Miguel, L. F. \& Biroli, F. (2008). Gênero e política no jornalismo brasileiro. Revista Famecos. (36), pp. 24-39. Recuperado el día 14 de agosto de 2013 de

http://revistaseletronicas.pucrs.br/ojs/index.php /revistafamecos/article/viewFile/4412/3311.

- Rocha, L. (2012). A Luta das mulheres e a reforma política. Mátria: a emancipação das mulheres. vol. 1 (10), pp. 15-16.

- Sanematsu, M. \& Melo, J. V. (2012). Cobertura sobre mulheres na política nas eleições de 2010: uma oportunidade perdida de aprofundar o debate. En J. E. D. Alves; C. R. J. Pinto \& F. Jordão (Orgs.), Mulheres nas eleições 2010 (pp. 479518). São Paulo: ABCP/Secretaria de Políticas para as Mulheres.

- Senado.gov.br. (2013). Participação da mulher na política brasileira cresce de forma lenta. Recuperado el día 24 de mayo de 2013 de http:/ / www12.senado.gov.br/noticias/materias/ 2013/05/21/participacao-da-mulher-na-politicabrasileira-cresce-de-forma-lenta.

- Tse.jus.br. (2013). Há 80 anos mulheres conquistaram o direito de votar e ser votadas. Recuperado el día 5 de abril de 2013 de http://www.tse.jus.br/noticiastse/2013/Marco/ha-80-anos-mulheresconquistaram-o-direito-de-votar-e-ser-votadas.

\section{Forma de Citación}

PARNAIBA, Cristiane dos Santos y GOBBI, Maria Cristina: Mulheres na política e na mídia brasileira: breve histórico e cenário atual. Womens in politic and brazilian Media: A brief history and actual stage. Revista Communication Papers, $N^{\circ}$ 3, páginas 51 a 63. Departamento de Filología y Comunicación de la Universidad de Girona. Recuperado el _ de_ de 2 de: http://www.communicationpapers.es 